\title{
Regionalismo literário e sentidos do sertão
}

\author{
Albertina Vicentini*
}

\begin{abstract}
Resumo: $\mathrm{O}$ artigo averigua a noção de sertão dentro do regionalismo literário brasileiro. Desenha um panorama geral de como essa noção vem configurando diferentes regionalismos e como ela parece se comportar tematicamente hoje, cada vez mais fluida e circunstancializada, a partir da semântica acumulada de espacialidade e cultura. Conclui pela importância de incluir nos estudos atuais sobre o tema a parelha interior-cidade grande, pelo menos em literatura.
\end{abstract}

Palavras-chave: literatura brasileira; literatura regionalista; sertão.

É tema deste trabalho a literatura regional sertanista, cuja discussão é complexa, porque envolve conceitos relevantes, como os de região, literatura regionalista e sertão, conceitos fluidos, escorregadios, que parecem não poder ser elaborados de maneira clara. São dependentes de contextos diversos, utilizados em diferentes áreas, como literatura, pensamento social, planejamento governamental, pesquisa universitária, discurso cotidiano, com diferentes fins, e recuperados, a cada vez, em diferentes perspectivas.

O que teremos, então, são alguns apontamentos sobre esses conceitos que a literatura regionalista em geral e a goiana em particular dão a conhecer a partir da sua produção literária. Desde já assinalamos que o sertão é uma coordenada específica de algumas literaturas regionalistas, uma vez que nem todas trabalham com essa temática: o Sul, por exemplo, tem os pampas, não o sertão.

Nesses termos, iniciamos assinalando o que essa literatura tem apresentado como conceito de região. Desde o começo da corrente, do século XVII até os nossos dias, a literatura tem entendido a região como um mundo já elaborado,

* Doutora em Teoria Literária e Literatura Comparada pela USP e professora do Mestrado em Letras da UCG. matéria pronta, que enfatiza espaços físicos, história, usos, costumes, imaginários específicos e regimes interpessoais (exóticos ou não), cobertos pela experiência no sentido benjaminiano do termo, cujo conteúdo se resolve num poema ou numa narrativa, ambos fictícios. ${ }^{1}$

Na resolução literária dessa matéria pronta pelo discurso narrativo, a literatura faz ressaltar a perspectiva histórica que embasa os acontecimentos. Toda narrativa é, fundamentalmente, temporalidade passada ou presente, sucessão de acontecimentos que ocorrem a um indivíduopersonagem, que deve agir num determinado espaço e contracena com outros personagens. Ao lado disso, por menor, mais frouxo, ou menos incapaz que seja, o discurso narrativo sempre cria, inventa uma representação verossímil de mundo, o que significa que ela expressa também um imaginário e uma mentalidade, ou visão de mundo ou ideologia, esta última no sentido comum do termo.

1. Em artigo recente, de 2005, Gilberto Mendonça Teles faz um levantamento das principais obras da literatura brasileira em que a noção de sertão aparece. O artigo se intitula "O lu(g)ar dos sertões" e consta de uma publicação da Capes/PUC-RIO dos resultados de um grupo de trabalho de estudos lingüísticos e literários - Ibell - formado a partir de um intercâmbio Brasil-Espanha. O nome da publicação é Diálogos ibero-americanos (coord.: Gilberto M. Teles e org.: Júlio César Valladão Diniz). 
Portanto, região, em literatura, tem sido região nos seus aspectos físico, geográfico, antropológico, psicológico etc., subsumidos na história relatada (a temporalidade), seja ela dominantemente política, econômica, social e cultural, porque só a manifestação de todas essas facetas ao mesmo tempo é capaz de engendrar uma história no sentido narrativo do termo, isto é, uma totalidade de mundo representada. Até aqui, nada ainda distingue a literatura regionalista das outras literaturas, porque toda narrativa, qualquer que seja, apresenta esse embasamento histórico para a criação de mundos fictícios representados.

Só que a literatura regionalista, além disso, mantém um outro elemento-chave de resolução que é o seu caráter performativo de apresentação de uma identidade grupal $^{2}$ (não importando, hoje, se essa identidade cultural se manifeste no campo ou na cidade), com a totalidade de seu mundo representado mantendose como conteúdo primeiro. Por isso é que se diz que, mesmo quando trágico, sério, cômico, irônico, ou comezinho, o mundo representado da literatura regionalista é, sempre, também épico. E também por isso toda literatura regionalista se preocupa com as questões da verossimilhança do seu mundo representado, pretendendo-se o mais documental possível. A falta de verossimilhança pode levar ao nãoreconhecimento identitário do mundo focalizado e à destituição do caráter regionalista do texto.

Os documentos, de seu lado, pretende-se que sejam todos verificáveis: são a linguagem da região, a fauna, a flora, os ofícios, os espaços, os comportamentos, as roupas, as situações, os climas, o jeito de ser, o nível mental, os problemas regionais, as crenças, o universo ideológico e por aí vai - matéria épica porque matéria pronta recolhida e apresentada para expressar uma identidade regional.

Essas são razões por que os escritores regionalistas dizem-se também pesquisadores, recolhedores de anotações em cadernetas. Publicam miscelâneas de lendas, cancioneiros, folclore recolhido, provérbios, dicionários de

2. Sobre o sentido performativo do discurso proferido sobre a região, ver: BOURDIEU, Pierre. A identidade e a representação. Elementos para uma reflexão crítica sobre a idéia de região. In: O poder simbólico. Lisboa: Difel,1989. termos típicos, livros de receitas etc., todos dentro ou ao lado de suas obras literárias propriamente ditas. E também se lançam em polêmicas infindáveis sobre a fidelidade da representação de mundo que suas obras apresentam - se de fato é ou não é assim a sua região; se aconteceu ou não do jeito que está relatado. E defendem a posição de que só o nativo ou o enraizado no local é capaz de ler, entender e transmitir essa identidade regional.

A questão da identidade, então, como conteúdo-chave dessa narrativa aponta para o processo de alteridade, jogo de semelhanças e diferenças, de partes e de totalidades, que culminam em auto-afirmações que se assinalam deícticas, quer dizer, se auto-afirmam a partir do locutor e do contexto, e deles depende. Todo regionalismo literário é assim, mesmo se brasileiro, goiano, hispano-americano, francês, inglês etc.

No caso brasileiro, o percurso histórico da literatura regionalista e, portanto, da identidade regional inicia-se com as primeiras manifestações literárias do sertanismo árcade e romântico do final do século XVIII e meados do XIX, em alguns sonetos de Cláudio Manoel da Costa e expressão romântica de Alfredo de Taunay e José de Alencar. Mas define-se de fato como corrente sistemática a partir do final do século XIX, com o mineiro Afonso Arinos, entrando século XX adentro com o gaúcho Simões Lopes Neto, os paulistas Valdomiro Silveira e Monteiro Lobato e o goiano Hugo de Carvalho Ramos no início do século até os anos 20; com o grupo nordestino de Graciliano Ramos, José Lins do Rego e Jorge Amado pelos anos 30; com o mineiro Guimarães Rosa e os goianos Bernardo Élis e Eli Brasiliense pelos anos 50; com, no caso da literatura goiana, José Godoi Garcia, Carmo Bernardes e Bariani Ortencio pelos anos 70; e duas expressões recentes - uma sergipana, outra paulista - de Francisco Dantas e Antonio Torres, para citar os mais conhecidos de todos nós, porque regionalistas há em todas as regiões.

Mas dizer que a literatura regionalista é expressão pretensiosamente documental de uma totalidade de mundo afirmativa de uma identidade grupal também não pode bastar para definila, porque outras literaturas também o são: há a etnografia do cortiço, por exemplo, como 
expressão típica da ocupação espacial marginalizada das cidades, empreendida por Aluísio de Azevedo em obra homônima; ou, atualmente, a literatura neonaturalista sobre a violência urbana, e tantas outras. Isso significa que um recorte temático que aponte de que grupo se quer mostrar a identidade, ao lado de como se fala desse grupo, também é importante para definir a literatura regionalista.

Nesse sentido, o recorte temático principal em torno do qual a literatura regionalista tem trabalhado seus temas e seus conteúdos identitários é, especialmente, o mundo rural, mundo dentro do qual se encontra o sertão, que nos interessa aqui. ${ }^{3}$ Historicamente falando, esse mundo rural vem sendo caracterizado de forma bastante dicotômica, por algumas parelhas, que oscilam entre a negatividade e a positividade, mas que se apresentam sempre por acumulação, embora de forma dominante. Primeiro, a parelha litoral \& sertão (que se inicia com a Carta de Pero Vaz de Caminha e culmina numa obra como a de Euclides da Cunha, que não é um regionalista literário, mas que discutiu a região fundamentalmente nesses termos, ao lado da questão da raça e do meio). Mais à frente, na representação de Taunay e de José de Alencar, a parelha campo \& cidade, imperiosa até hoje na música ou na literatura, com a expressão ímpar de Guimarães Rosa a partir de meados dos anos 40. No final do século passado, com o surgimento dos estudos etnográficos e folclóricos de Couto de Magalhães e Sílvio Romero, precedidos ainda por José de Alencar, a parelha Norte \& $\mathrm{Sul}$, desdobrada, a partir do romance nordestino de 30, em Norte, Nordeste, Sul, Centro-Oeste e Sudeste. Posteriormente, desde Monteiro Lobato até hoje, a parelha interior \& capital, que nos parece ser o âmbito básico do atual regionalismo.

Além disso, o sertão também vem sendo recortado como elemento de uma totalidade que se situa num outro lugar propriamente falando, distanciado de tudo (o contraponto ainda é feito por oposição) e em todos os sentidos possíveis. Há o sentido espacial - o sertão é o interior longínquo e despovoado, ou povoado por uma

3. Essa relação pode ser conferida em praticamente todos os compêndios de história da literatura brasileira no século $\mathrm{XX}$. Não faremos as citações aqui, por muito extensas. raça mestiça, ou o locus amoenus das bucólicas greco-romanas; o sentido econômico - o sertão mantém uma economia distante da economia da metrópole e do litoral, agrária e subdesenvolvida em face da economia industrial e mais desenvolvida da metrópole; o sentido social -o sertão mantém outro tipo de associação de membros, uma associação mais comunitária, outro tipo de usos e costumes; a aliança sociopolítica - o poder dos coronéis, o desvalimento dos camaradas, a luta social dos estados periféricos; o sentido psicossocial, na perspectiva da antropologia - o sertão detém um universo psíquico mais ritualizado, com formas de pensamentos mais míticas e agônicas; o sentido histórico - o sertão detém a chave de nossa origem histórica típica e genuína, a partir das entradas e bandeiras, por exemplo, e o sentido do imaginário propriamente falando quando o sertão avulta como local de vida heróica ou trágica, de vida salutar e genuína, ou de vida identitária. E outros tantos, que salientam uma perspectiva romântica, ou realista, ou conservadora, ou de denúncia social, ou determinista etc..

Dessas perspectivas, várias relações podem ser feitas: a que associa a noção de sertão com terra desconhecida, inóspita, ignorada e bárbara, como fez Euclides da Cunha; a que associa sertão à ruralidade e ao campo, com estudos da sociologia rural ou a produção intelectual da literatura regionalista, por exemplo; a que associa o sertão à noção de fronteira econômica, e que faz com que os planejamentos governamentais o encarem como terra a conquistar para construir o futuro da nação; a que associa o sertão à identidade da nação e cria com ela o povo étnico brasileiro e as suas principais características culturais e raciais diferenciadas do conjunto das outras nações; a que associa o sertão ao subdesenvolvimento e ao primitivismo, merecedores de uma colonização civilizatória, para só citar algumas.

O que essas parelhas delimitam em comum parece ser o recorte espacial de temática, o que levaria a supor que os processos da temporalidade narrativa que empurram o conceito de região na literatura de que já falamos nele não poderiam entrar. Mas não é o caso. Se a questão do espaço, pelo menos em literatura, se mantém 
muito pelo suporte do enunciado da descrição - muito típica do regionalismo, inclusive -, ela também só se resolve em outros suportes que integram essa descrição, que são $o$ cenário e a história relatada, com o seu mundo representado. Em literatura, cenário é lugar, decoração, pintura, paisagem, flora, fauna etc., mas também é cena, lugar onde acontecem as ações praticadas pela rede dos personagens, lugar de onde se fala, componente concreto da percepção do tempo abstrato - a mudança de cenário releva mudança de ação, tempo, mesmo que simultâneo. Enfim, é paradigma social e aspectual. Um cenário, para não pecar em literatura, deve ser sempre um cenário também social. Ainda, é um dos elementos que determinam o conjunto de oposições e interações possíveis entre os personagens, recortados em dêixis: os daqui, os de lá, o estrangeiro, o autóctone, o eu, o aqui, o tu, a aldeia, a cidade etc, fundamentais para a apresentação daquela matéria pronta de que falamos atrás: uma sinédoque continente/conteúdo - o continente que suporta os diferentes conteúdos que representam a identidade. Isso além de ser passível de agregar outros sentidos simbólicos e metafóricos - espaços que são concretos e psicológicos ao mesmo tempo, por exemplo, ou míticos, como a floresta e o cerrado, de motivação realista, atmosférica etc (veja-se, por exemplo, as veredas de G.Rosa.).

Evidente, essas parelhas são e não são específicas da literatura, quer dizer: são específicas porque com elas a literatura nos dá a conhecer o mundo que relata (enquanto desconhece outras) - toda narrativa literária, ou pelo menos toda boa narrativa literária, trabalha com acontecimentos particulares e recortados em tempo e espaços particulares que levam a uma representação de mundo total que tanto melhor será quanto mais universal conseguir ser representativo do que poderia ser (não do que é). Mas essas parelhas também não são específicas da literatura, porque fazem parte do pensamento histórico e social propriamente dito, que as reelabora em termos políticos, sociais, econômicos, uso de poder, distribuição, reconhecimento etc., para servirem justamente de esteio à verossimilhança do mundo representado que a literatura regionalista nos dá a conhecer.
Isso de um modo geral, bem geral. Toda e qualquer literatura regionalista tem discutido, enfatizado ou reelaborado uma ou várias dessas parelhas, ao lado de outras, específicas, e é justamente isso que a reparte em várias literaturas regionais identitárias: a nordestina, a nortista, ou a sulina que, por sua vez, poderão ser repartidas em tantas outras mais locais ou pontuais, não importa, inventando o que vem e pode ser chamado de um regionalismo mineiro, goiano, gaúcho, paulista, baiano, ou local, como o da Região da Mata em Minas Gerais, ou do sudoeste goiano, e por aí vai, sempre de olho na história e nos espaços que recebem a matéria dada. E tudo isso ao lado das diferenças linguiísticas e estilísticas de autor, lugar e das instituições literárias de gêneros, formas etc.

Podemos exemplificar isso com o regionalismo goiano. O que a história da literatura goiana tem dado como conteúdo identitário a partir de algumas coordenadas temáticas que diferenciam o nosso regionalismo dos demais, num rendilhado de igualdades e diferenças fundamental à recuperação de cada um desses espaços focalizados, são:

a) a noção de sertão, aqui entendido como extensão de terra que se contrapõe ao litoral, povoado de fazendas e cidadezinhas interioranas, matas, rios, é certo, mas já destituído o litoral do interesse que pode ainda suscitar no regionalismo baiano, por exemplo, que conflui litoral e capital. Ainda, sertão, para o regionalismo goiano, também não equivale ao sertão da maneira como ele é significado no Nordeste - que tem como uma de suas principais coordenadas temáticas a seca e a miséria, porque Goiás não tem a seca rotineira e deflagradora nordestina. Sertão goiano envolve, para além do espaço que distancia a imensidão de terras despovoadas para lá do mundo civilizado da capital, algumas coordenadas históricas do estado, quais sejam: a mineração (que não está presente no Nordeste), o bandeirantismo e o gado, coordenadas que confluem o sertão goiano, fazem-no assemelhar-se aos sertões mineiro e paulista, de um lado, e ao mato-grossense de outro. Mas com a diferença de que a mineração em Minas, por exemplo, liderou ou executou uma história de poder e influên- 
cia em âmbito nacional que a mineração do sertão goiano não empreendeu; também, o bandeirante paulista foi elemento agente fora de São Paulo, e o bandeirantismo em Minas e Goiás foi elemento paciente. O sertão mato-grossense, por exemplo, também manteve questões de fronteira que não aconteceram em Goiás, pelo menos não em relação a países estrangeiros, impôs a temática do Pantanal e das águas como ênfase identitária, acercou-se de um imaginário de guerra que o aproximou do regionalismo sulista e reelaborou as questões indígenas que Goiás também teve, e de que se resguardou na sua literatura. ${ }^{4}$ Dessa forma, a literatura vai registrando essa temática. Por Goiás, os acontecimentos de um mundo capaz de criar identidade são acontecimentos localizados nesse espaço histórico de sertão relatado: um texto como "A madre de ouro", de Hugo de Carvalho Ramos, é representação dessa coordenada histórica da mineração. Não seria um produto do regionalismo literário nordestino, da mesma maneira que o livro Vidas secas, de Graciliano Ramos, não seria, tal qual ele é, em algumas de suas temáticas, produto de um regionalismo goiano;

b) uma segunda temática, proveniente da perspectiva ativa do bandeirantismo, é a de sertão como terra a conquistar, portanto fronteira de expansão e de economia. Consolidada no regionalismo goiano, aparece primeiro nos tropeiros e boiadeiros de Hugo de Carvalho Ramos, no livro Tropas e boiadas, que é uma reedição do bandeirantismo expressada na mobilidade literal do tropeiro e do gado e da produtividade econômica deste último. A seleção da figura do boiadeiro e não do roceiro como personagem centrais dos contos do livro aponta uma forma histórica de integrar Goiás como um estado

\footnotetext{
4. Por incrível que pareça, não há, na literatura regionalista goiana, um cancioneiro expressivo cuja temática fosse as lutas indígenas entre bandeirantes - primeiros sertanejos apossadores do território - e os caiapós, por exemplo, que estão presentes na formação histórica do nosso sertão (o que, evidentemente, pode encontrar alguma explicação, pelo menos no caso da literatura regionalista goiana, no seu início tardio, já no século XX, quando outras questões interessavam mais ao estado, o que volta a comprovar que a literatura é também uma forma histórica de um tempo, de um poder, de uma classe etc.)
}

produtivo no concerto maior da nação do início do século, e que, afinal, não passou (e não passa) de uma eleição ou seleção ideológica de formas históricas disponíveis. ${ }^{5}$ No entanto, essa temática se firmou especialmente pelo cenário extraliterário da política - que a Marcha para o Oeste de Getúlio Vargas e a Fundação Brasil Central de Juscelino vieram reforçar - e ainda se representa na atualidade, por exemplo, na figura clara de Ramiro, personagem de Jurubatuba, de Carmo Bernardes, boiadeiro supimpa, bom caráter, trabalhador produtivo, que põe ordem e disciplina comportamental e econômica na fazenda onde atua;

c) a temática política das lutas de poder internas ao estado e do regime político do coronelismo, provenientes do processo político histórico nacional e não necessariamente regional, mas que aqui se mistura à temática da cidade do interior. ${ }^{6}$ Obras como $O$ tronco, de Bernardo Élis, ou Uma sombra no meio do rio, de Eli Brasiliense, comprovam decididamente essa especulação histórica regional;

d) e, finalmente, a questão do regime de estamento e de trabalho, de exploração da mãode-obra do sertão, o regime de camaradagem, em que o trabalho é pago por salários que se transformam em dívidas de custeio de bens materiais, escravizando o trabalhador rural ao seu patrão-fazendeiro ou fazendeirocoronel, que gerou as primeiras vozes de denúncia social regionalista através de Hugo de Carvalho Ramos, na sua novela "Gente

5. O roceiro existia no sertão goiano, mas não era convincente ao tempo falar dele, porque era detratado, como comprova o texto "Velha praga" de Monteiro Lobato e a sua figura do Jeca Tatu. Ideologia que pode ser lida nas representações de mundo dos contos de Hugo de Carvalho Ramos, nas suas estórias, e naquelas representações de mundo e de estórias que ele deixou de narrar, o universo ideológico apagado de qualquer texto, e que poderiam ser eleitas como representações que levariam a outros imaginários e a outras ideologias, que cumpririam outros interesses históricos etc. e confirmariam outras identidades para o estado de Goiás.

6. Diferentemente de Minas, que produz um componente de lutas políticas no espaço também da fazenda e do sertão ou das veredas, como é o caso de Guimarães Rosa, para além do registro dessa temática em pequenas cidades interioranas, como em Vila dos Confins, do também mineiro Mário Palmério, trazendo como elemento histórico o conflito armado. 
da gleba" e em contos como "Peru de roda", coroados pelo célebre "A enxada" de Bernardo Élis, e, secundariamente, pelo romance Pium de Eli Brasiliense, estórias de trabalhadores rurais e garimpeiros, ambos dos anos 40;

e) outras temáticas, inúmeras delas, já interfaceiam o regionalismo goiano com outros regionalismos, como: a temática erótica da moça sertaneja, que aparece em quase todos os romances e contos regionalistas de diferentes épocas - moça fruta do mato, como indica o próprio erotismo da metáfora; a temática da violência dos sertões, do homem em estado instintivo, ou natural, como quis o século XVIII, gerada pelo imaginário longínquo da Carta de Pero Vaz de Caminha, que dizia que o sertão era o desconhecido para além do que se via das caravelas, adentro do mato, lugar de bicho. Ao que as bandeiras acrescentaram o inóspito, o despovoado e o perigoso, a violência também fruto das guerras interinas estaduais, da representação da vida dura, da representação dos instrumentos cortantes, duros, e dos atos de cortar e abater bichos, plantas, e índios, que forjam o trabalho braçal desses espaços etc.; as histórias de amores violentos, apaixonados, trágicos, instintivos, desintelectualizados pela desmedida das ações, pelas reações primárias do sertão sem escola ou disciplina, ao lado da representação contrária do amor idílico, doce, angelical, exercitado em lugares amenos, bucólicos, bonitos, líricos, advindos de um imaginário quinhentista do Novo Mundo paradisíaco, ou do campo como lugar de autenticidade e essencialidade diante do artificialismo e da inautenticidade da cidade civilizada, como quiseram os românticos; a bizarrice, o exótico, o pitoresco desse mundo desintelectualizado, de proporções imensas - o sertão é imenso -, preso aos sentidos da vista e do ouvido, no modo sensorial de viver, que vê assombrações, decide por tradição, lugar de cobra-grande, de sucuris, de urutus, uma violência e bizarrice animais, de parelha com a bizarrice do falar do homem, da sua roupa, do seu comportamento, e por aí vai. Claro, sempre com algumas (poucas) especificidades literárias bastante conhecidas; f) e, por último, o regionalismo praticado como vitrine, principalmente nas escolas, nos teatros, nas farsas, na televisão, como exposição dos frutos da terra, regionalismo que encontra em Goiás o seu máximo representante no pequi destituído de história, destituído de universalismo, de particularismo até, ou o regionalismo de representação degradada do roceiro das festas juninas, das roceiras de vestido de chita. A vitrine utiliza os significantes pelos significantes meramente descritivos, que ameniza as suas ilações com imaginários e ideologias históricas. Os personagens da festas escolares não são confrontados com nenhum outro, mas são, antes, expostos, deixando perceber ou a sua conformação ao emblema, ou a sua degradação, ou a elevação de formas, não importa. Quaisquer que sejam, são exposição de receitas por receitas, culinária pela culinária, traje pelo traje, quase forma pela forma, de feição determinista, porque representam a terra, porque a terra os dá como fruto das suas árvores típicas ou da sua tradição, sem historicização: jogos de necessidades naturais ou ambientais, apagados semanticamente pela inconsciência e pela alienação daquilo que representam, dos que as representam e dos que assistem a elas.

Essas temáticas, no entanto, se não são do mesmo grau - as duas últimas são de tratamento mais estereotipado que as outras -, têm mantido diferenças no conjunto da chamada literatura regionalista, traçando-lhe fundamento e história, de um lado, e, de outro, reconhecimento e performatividade.

Todas essas relações, conceitos, recortes temáticos e contraposição vêm tentando, de um lado, desenhar, uns bem, outros mal, o que vem a ser sertão, pelo menos quanto às suas possíveis categorias de análise, muito embora ainda pouco se tenha percebido do desenvolvimento histórico e acumulativo, igual e diferente que cada um desses elementos traz. De outro lado, todas elas parecem esbarrar, hoje mais do que ontem ou do que no início da história brasileira, na materialidade, na realidade concreta do próprio termo que definem, até porque essas suas dicotomias são fundamentalmente espaciais. 
Hoje, “Onde fica o sertão?", pode-se perguntar. "Ali, mais adiante", quase sempre é a resposta. E essa pergunta e essa resposta parecem ser recorrentes.

Essa delimitação insistente pela espacialidade, e que tem ordenado e desordenado, assentido e complicado o conceito de sertão, talvez sobreviva por acumulação: quando os portugueses aportaram suas caravelas no litoral brasileiro, foi fácil perceber que o sertão era todo o espaço que para dentro das praias podia ser apenas vislumbrado e imaginado, mas não visto, como assegura Pero Vaz de Caminha em sua Carta. Sertão, aí, conseguia ser um elemento literalmente espacial e, de certa forma, concreto, mensurável. Parece que à medida que as entradas e bandeiras foram explorando esse interior espacial visto das praias, o sertão também foi caminhando rumo a essas categorias que hoje tentam defini-lo e que o constroem - o sertão foi o rastro deixado pelas bandeiras. Quando se passou a recortá-lo de dentro como cultura para além da espacialidade, a insistência no espaço, parece, passou a ser mantida também em função de uma busca das origens.

Hoje, o argumento que discute a homogeneização das diferenças por ação do capitalismo na construção dos diferentes espaços e paisagens diz que, com a empresa de porte industrial no campo, a telefonia e a eletricidade rurais, os insumos básicos industriais, os meios de produção motorizados, ou seja, as apropriações que o sertão faz das cidades, e que transparecem em suas novas formas culturais que já se associam de fato à urbanidade, fica muito mais difícil saber onde fica o sertão. O que significa que ele vem perdendo cada vez mais espacialidade e materialidade concretas, que sua cultura vai se constituindo cada vez mais no âmbito daquilo que, antropologicamente, pode ser chamado de arquétipo cultural, e que suas realizações concretas vão se tornando, também, a cada dia, mais tradição ou vitrine, ou patrimônio cultural, que qualquer outra coisa.

Daí a série de movimentos disparatados e conservadores da recuperação dessa cultura, como função compensatória que se instala nos estudos e produções que falam disso, como uma maneira de tentar salvar alguma coisa que vai se perdendo no tempo e no espaço.
A literatura regionalista já havia atinado com isso: qual a materialidade espacial do sertão, se o sertão está em toda a parte?, pergunta G. Rosa. E responde: "o sertão é o homem", e o que existe é "homem humano", carregado de cultura e história, atravessando o espaço, o tempo, as emoções, as experiências.

Isso, de novo, tem a ver com a história. $\mathrm{E}$ se esse argumento é bastante ponderado e aponta para um discussão de perda espacial (e cultural) histórica que de fato acontece, ele também suscita outras questões.

Primeiro, é preciso verificar que, desde que o sertão ganha cultura, as cidades vêm se apossando dele, até porque muito do que constitui a cultura do sertão foi apropriado dos homens citadinos que o desbravaram, que construíram e vêm construindo o seu espaço historicamente. E muito do que constitui a cidade hoje também tem a ver com o modo de vida dos habitantes desses locais construídos, seja historicamente, seja pelas condições sociais das migrações campo-cidade, por exemplo. Ou seja, com menos pureza e romantismo, essas situações de alteridade têm levado a construções de identidades numa totalidade e não em partes radicalmente separadas.

Depois, a ambigüidade que resulta de buscar o espaço onde fica o sertão hoje talvez seja mais inerente à sua construção originária do que à sua semantização: o primeiro discurso elaborado sobre o sertão (como está na Carta de Pero Vaz) aconteceu a partir de um lugar definido, determinando um outro lugar distanciado do emissor. Dessa forma, as suas primeiras coordenadas categoriais foram (e ainda são), portanto, deícticas, ${ }^{7}$ isto é, ligadas à situação do discurso e determinadas pelo espaço-tempo conjunto do emissor e receptor. Como categoria da dêixis, o sertão, realmente, não pode deter uma espacialidade única, porque depende, a cada vez, do lugar que ocupa o emissor do discurso ou o sujeito da enunciação. Mas o fato de ele deter uma espacialidade cambiante não significa dizer que não tenha uma identidade e categorias definidoras, isto é, uma semântica.

7. Cf. de novo Gilberto Mendonça Teles, quem primeiro introduz essa idéia, no já citado artigo da nota 1 e também em um outro, apresentado ao Coloque International de Rennes, França, em 1990 (mimeo.). 
Assim, podemos perguntar: determinar o sertão hoje, no nível prático, corresponde a localizá-lo cada vez mais circunstancialmente? Sertão está onde estão atualizadas as identidades que o definem, isto é, onde estão atualizados os seus postulados culturais? Por mais que perca em espacialidade, o sertão não se reduz mais a ela (embora ela se mantenha como categoria semântica acumulada historicamente) e, se não existe o sertão total, existem, no entanto, os sertões circunstanciais, pequenos, rendilhados, no campo, na cidade interiorana, na cidade grande, cruzados e delimitados pelas estradas de rodagem, pelos povoados, pelas pequenas cidades cobertas de antenas. Ou, para dizer como G. Rosa em Grande sertão: veredas: "o sertão, ah, o sertão está em toda parte"; "o sertão está dentro de nós"; "o sertão é o que não tem fim"; “ o sertão é o sertão"; "o sertão tem muitos nomes". O sertão é o que atualiza categorias de uma cultura historicamente diferenciada (e que se diferencia historicamente a cada dia) mediante estruturas sociopolíticas e econômicas.

Falar da perda do sertão dentro de um processo de homogeneização da cultura estabelecida pelos ideários da produção do espaço capitalista finda, então, por "generalizar através de regras comuns aquilo que não é uniformizável: desenvolvimento desigual e articulado do próprio capitalismo no interior da formação social", como assegura Paulo Henrique Martins (in Silva, 1990). A produção de um espaço apenas é possível de se realizar através de um duplo movimento: homogeneização e heterogeneização. "O capital apenas pode uniformizar o espaço através de novas segmentações que ele mesmo cria" (in Silva, 1990) - o que significa que a extinção de uma forma é antes um contexto de transformação e ou recriações de novas formas, que se transformam, mas não desaparecem necessariamente, até porque implicam uma cultura.

Nesses sentidos e nessas discussões, ademais, é que o sertão vai revendo o conceito de região, principalmente o elaborado pela perspectiva administrativa do Estado brasileiro, ${ }^{8}$ e é

8. Muito embora a chamada literatura regionalista siga adjetivando-se até mais burocraticamente ainda dentro dessa perspectiva, como goiana, mineira, gaúcha, coincidindo com os estados-províncias, e fazendo coincidir, contradito- muito notadamente aí que ele aparece concreta e culturalmente como diferentes sertões, assinalando diferentes microrregiões dentro da macro, particularizando e historicizando a totalidade. De um lado, portanto, há as categorias que historicamente definem o que é o sertão, indicam seus dados culturais principais desde sua remota aparição, generalizam-se como regionais de Sul, Sudeste, Centro-Oeste, Nordeste, Norte e, de outro, as atualizações de múltiplos sertões, pequenos, rendilhados, recortados, diferentes das totalidades, e que recriam essas categorias acumulativa, dialética e diferencialmente a partir de seus dados culturais.

Entre esse igual e diferente, e as preocupações com a materialidade espacial, o pensamento social brasileiro vem reiterando essas dicotomias, com a sua especificidade e modificações. Especificamente hoje, ela parece recortar a sua temática em formas como as que se seguem.

Primeira, em uma tríade, em que um termo se mantém subentendido e um outro aparece mais enfaticamente: sertão-cidade do interior-capital (ou cidade grande), em que o sertão vira expressão cultural mais paradigmática que sintagmática e cede sua espacialidade, paisagem, geografia, "causos", acontecimentos, conflitos etc. ora para a cidade interiorana, ora para a cidade grande, principalmente para a sua periferia. Na literatura regionalista, já com Monteiro Lobato, em Oblivion, e Graciliano Ramos, em Angústia, isso vinha se desenvolvendo. Na atualidade, o romance Essa terra, de Antonio Torres, pode ser um grande exemplo disso, conforme já assinalamos em outro artigo nosso. ${ }^{9}$

riamente, no seu nome, aquilo que ela contraria na sua realização, isto é, cultura e estado burocrático.

9. Cf. nosso artigo "O sertão e a literatura", publicado na Revista Ciências Sociais, UFG: v.1, n.1, jan./jun. 1998. Resumimos: o romance conta a estória de Nelo, rapaz nascido no campo, que deixa a cidadezinha interiorana para a qual tinha ido criança, Junco (BA), e vai para a cidade grande realizar sonhos. Fracassado, retorna a Junco, onde é recebido como vencedor, farsa que não consegue sustentar, matando-se no dia seguinte ao da sua chegada, para perplexidade e frustração de todos, especialmente da mãe, que enlouquece, e de Totonhim, irmão mais novo, que seguirá a trilha do irmão para São Paulo. O universo de Junco, não o da cidade grande ou o do sertão, é o retratado: a mentalidade dos habitantes, os tipos da cidade do interior, suas estórias, formados a partir da matriz da família sertaneja que sai do 
$\mathrm{Na}$ literatura goiana, o romance Nunila, de Carmo Bernardes, assume essa temática. Esse romance deve ser ligado a um anterior, Jurubatuba, porque recorre ao mesmo personagen principal. Ramiro (falso nome de Lino, que deixa a fazenda Jurubatuba e segue para a cidade interiorana de Descoberto, onde de fato se passam os acontecimentos).

Uma segunda forma é nova e tem suas raízes nas ciências biológicas e geográficas, mas se desenvolveu principalmente no âmbito político-econômico e recobre muito do que é (foi) o sertão de Minas e Goiás. É o cerrado com todas as suas implicações de espaço, fauna, flora e, muito particularmente, produtividade econômica. ${ }^{10}$

É claro que o cerrado traça limites, fronteiras regionalizadas: se sertão era um nome que, de uma maneira ou de outra, recobria as Regiões Norte, Nordeste e Centro-Oeste, cerrado é um termo (e um conjunto de significados) que se liga à região central (Goiás e Mato Grosso e uma parte de Minas e São Paulo) de forma mais específica.

Aliás, foi à região central que, historicamente, o termo se vinculou, notadamente pela época da construção de Brasília, o que indicia a sua aliança com a noção de fronteira. De fato, as suas primeiras recorrências de significação aliavam-se à "descoberta" (e, portanto, inauguração) da sua possibilidade produtiva em termos de agricultura, até então considerada meio que economicamente inviável em terras como as do cerrado. Tanto é que as primeiras observações a esse respeito vieram das administrações e governos biônicos dos anos 60/70, que quiseram

campo assolada pelo capitalismo da monocultura - o pai, as filhas, o irmão -, mas que retém as coordenadas do sertão. Dividido em quatro partes de títulos significativos: "Essa terra me chama"; "Essa terra me enxota"; "Essa terra me enlouquece"; "Essa terra me ama", afinal, de qual terra se fala no texto, dado que o deíctico 'essa' não aponta um lugar nem perto (para o que se usaria 'esta') nem longe (para o que se usaria 'aquela')? A resposta pode ser de todas, de cada uma delas, ou de nenhuma. Estilisticamente, o livro se fragmenta em muitas narrativas: narrador - autor de terceira pessoa; a mãe; Nelo; Alcino, o louco da cidade, e outros, mantendo estórias lacunares que fragmentam a narrativa em muitas vozes e episódios, desrespeitando, como é da narrativa moderna, a cronologia, a linearidade.

10. Significativamente, uma das mais recentes publicações regionais é $O$ pequeno livro do cerrado, de Gil Perini. SP: Editora Giordani, 1999. implantar em Goiás, por exemplo, projetos econômicos, como os do Rio Formoso (governo Ary Valadão). Fauna, flora e geoambiente significam o cerrado. Hoje, parece ganhar o elemento humano na expressão que já é usual pela região central - "povos do cerrado". Mas essa troca é absolutamente pragmática e significa, antes de tudo, a perda de história e de cultura. Sertão continha ambos; cerrado é produtividade econômica e geografia, territorialidade desprovida de imaginário, de literatura etc.

Terceira, a do confinamento da palavra sertão. Esses outros usos e nomenclaturas fizeram com que a palavra sertão se aliasse muito mais à seca nordestina que a qualquer outra região do país, implantando certo monopólio de sentido que, desde Euclides da Cunha, tentava se firmar e que os meios de comunicação de massa acabaram por determinar. Hoje, sertão é muito confinado ao Nordeste do país.

De qualquer maneira, parece que qualquer investigação que se faça hoje sobre a literatura regionalista e o sertão deve pretender responder pelo comportamento dessas temáticas, especialmente dentro da relação interior-capital, partindo da hipótese de que essa dicotomia mantém, mesmo que oculto, conforme exposto, o tema do sertão como elemento-baliza, o que o tema do cerrado ainda não deixa entrever.

\begin{abstract}
This essay studies the notion of "sertão" in the Brazilian literary regionalism. It establishes a general view of how this notion configures different regionalisms and how it seems to work thematically nowadays, in a more and more fluid and circumstantialized way, always in relation to its spatial and cultural meaning.
\end{abstract}

Key-words: Brazilian literature, regionalism, "sertão".

\section{Referências}

BOURDIEU, Pierre. A identidade e a representação. Elementos para uma reflexão crítica sobre a idéia de região. In: 1989. . O poder simbólico. Lisboa: Difel,

CONGRESSE INTERNATIONALDERENNES. Atas. France, 1990. (Mimeografado).

MARQUES, Reinaldo et. al. (Org.). Limiares críticos. Ensaios de literatura comparada. Belo Horizonte: Autêntica, 1998. 
PERINI, Gil . O pequeno livro do cerrado. São Paulo: Editora Giordani, 1999.

SCHETTINO, M. Espaços do sertão. Brasília, 1995. Dissertação (Mestrado).

SILVA, N. (Org. ) A República em migalhas. Rio de Janeiro: Marco Zero, 1990.
TELES, G. M.; DINIZ, J. C. (Orgs.). Diálogos iberoamericanos. Rio de Janeiro: Edições Galo Branco, 2005.

VICENTINI, A. A narrativa de Hugo de Carvalho Ramos. São Paulo: Perspectiva, 1986. (Col. Debates). O regionalismo de Hugo de Carvalho Ramos. Goiânia: Cegraf/Editora da UFG, 1998. 